\title{
Simulation, Co-cognition, and the Attribution of Emotional States
}

\author{
Bill Wringe
}

In the past fifteen years, many philosophers and psychologists have discussed the question of how the human capacity to attribute mental states to other human beings is best explained. ${ }^{1}$ On one account - the theory view - it depends primarily on our possession of a body of knowledge about relationships between the environment, mediating mental states, and behaviour. An alternative view the simulation view - is that possession of a theory does not play this primary role in explaining our capacity for attributing mental states to other people. On this view, the capacity in question depends on our having an ability to simulate other people's mental processes. Furthermore, our capacity to simulate other people's mental processes is not itself to be explained as being the result of our possession of a body of theoretical knowledge. ${ }^{2}$

At first sight, this might appear to be a relatively arcane debate, primarily of interest to specialists in a fairly narrow area of naturalistically inspired philosophy of mind, and philosophy of cognitive science. In fact, though, its ramifications run deep. What is at issue is the question of whether our everyday understanding of other human beings is based on the same sorts of mechanisms which we bring to bear in our understanding of the natural world or whether it is sui generis. It is likely that the answer to this question will have implications for a range of other philosophical issues, such as the epistemology of other minds, the metaphysics of persons and mental states, and the scientific status of the social sciences. $^{3}$

The debate between advocates of the theory and simulation views has mostly focussed on the question of what is involved in attributing beliefs to other people. Other kinds of mental states, including emotions, have received less attention. ${ }^{4}$ This is both surprising and significant. It is often thought that, if true, the simulationist view must have a certain degree of generality. Without such generality it could not have the wide ranging consequences it is sometimes claimed for it. But a simulationist account which is only an account of belief attribution does not have such generality. Our beliefs do not constitute the sum or even, necessarily the most important part of our mental lives. Nor is our capacity to attribute beliefs necessarily the most significant or striking aspect of our ability to enter into the minds of others.

European Journal of Philosophy 11:3 ISSN 0966-8373 pp. 354-374 (C) Blackwell Publishing Ltd. 2003. 9600 Garsington Road, Oxford OX4 2DQ, UK, and 350 Main Street, Malden, MA 02148, USA. 
Even if we are skeptical about whether the simulationist view does have the wide-ranging consequences sometimes claimed for it, the question of whether the simulationist account of belief attribution generalises is still significant. If the simulationist account cannot be extended to cover the emotions, then it has less going for it than one of its most important theoretical rivals - the theory view. ${ }^{5}$ So even if we are only interested in the theory/simulation debate, and not in its wider ramifications, the question of whether the simulationist account can be extended is still an important one.

In this paper I argue that there is indeed a viable simulationist account of emotion attribution. However, I also try to do more than this: I aim to say something specific about the form that this account ought to take. I argue that someone who wants to give by a simulationist account of emotion attribution should focus on similarities between emotions and perceptual judgments. Since this claim is central to my position, I shall say something more about it here.

One might hold that the job of extending a simulationist account of belief attribution to cover emotions was not a particularly difficult one. A striking feature of many recent philosophical accounts of the emotions is their stress on the kinship between emotions and cognitive phenomena such as beliefs and judgments. Indeed some accounts have even gone so far as to suggest that beliefs might be either partly or wholly constituted by beliefs and judgments. If this view is correct, then turning a simulationist account of belief attribution into an account of emotion attribution may involve little more than noting that some emotions are either identical with, or partially constituted by judgments.

Unfortunately, this line of argument turns out to be unsuccesful. The kinship between emotions and cognitive phenomena is significant ${ }^{6}$ and provides us with some reason for hoping that it will be possible to extend the simulationist account to cover emotion attributions. However, as I shall try to show, the parallels between emotions and judgments break down at a key point. The problem is that emotions do not seem to play the same role in deliberation as beliefs and judgments typically do. ${ }^{7}$ It is for this reason that we need to look at the parallels between beliefs and perceptual states in formulating a version of the simulation view. $^{8}$

\section{II}

I shall start by giving a fairly schematic characterisation of the simulation and theory views. ${ }^{9}$ This will help to give us an idea of the difficulties that lie in the way of a simulationist account of emotion attributions, and the resources that are available for overcoming them.

The central idea of the theory view is that our capacity to ascribe mental states depends on our application of a body of knowledge about mental states and the causal relationships between them, the environment and behaviour. It is also typically part of the theory view that the body of knowledge involved has a

(C) Blackwell Publishing Ltd. 2003 
degree of structure, precision and abstraction which make it worth calling it a theory. $^{10}$

As Stich and Nicholls (Stich and Nicholls 1995a) point out, we can see the theory view as an involving an appeal to an explanatory strategy which is more or less standard in cognitive science. According to Stich and Nicholls, use of this strategy seems appropriate because there is no obvious reason why an explanatory strategy which can account for our capacity to judge the grammaticality of a sentence or to follow the trajectory of a flying ball should not succeed in explaining our capacity to attribute mental states to human beings as well. ${ }^{11}$

By contrast, the key point of the simulationist position is that our capacity to ascribe mental states to others can be explained by appeal to our possession of a capacity to simulate other people's mental processes. On pain of seeing their position collapse into a notational variant of the theory view, simulationists also need to hold that we can possess a capacity for simulation without possessing a theory about mental states. ${ }^{12}$ This second claim is defended by appealing to a distinction between cases where a person's ability to simulate something depends on their possessing a theory about it and cases where it does not.

A well-worn example can illustrate the point. Someone who wants to simulate the flow of blood in a human being in a scale model will probably need to draw on some theoretical knowledge about the way in which blood flows in real human beings in order to construct the model. ${ }^{13}$ If someone provides me with a ready made scale model then I do not need much in the way of theory. ${ }^{14}$ Simulationists hold that when it comes to simulating other people's mental processes, I am in the position of someone who has been provided by nature with something which can function as a scale model, rather than someone who has to construct one.

Why should we think this is true? A simple answer would be that human minds are similar to one another in various important respects. However, in what follows it will be worth distinguishing between three sorts of similarities which play a part in simulationist accounts of mental state ascription. These are shared perceptual capacities, shared inferential dispositions, and shared standards of rationality. ${ }^{15}$ To the extent that we do share these capacities, dispositions and standards our minds work in more or less the same way. As a result it is reasonable to think that when someone is trying to work out what someone else is thinking, they can make a good start on doing so by considering what they would think if they were situated as they take another person to be situated. ${ }^{16}$

\section{III}

Much of the debate between advocates of the simulation view and advocates of the theory view has focused on the question of what is involved in attributing beliefs to someone else. Given my sketch of the simulationist view, this is unsurprising. Beliefs are paradigmatic examples of mental states which are conceptually informed and responsive to perception and norms of rationality.

(C) Blackwell Publishing Ltd. 2003 
Indeed, one might even think that, given some important adjustments having to do with the role of beliefs in the production of action, there is not much more to say about them at all. However, for the simulationist view to be at all plausible as a general account of mental state attribution, there must be at least a possibility of extending it so that it applies to the emotions.

How easy it will be to make an extension of this sort depends on one's view of the emotions, and particular, on the relationship between emotions and other kinds of propositional attitudes, such as beliefs and desires. On the face of it, the more similarity there is between emotions and other kinds of mental states, such as beliefs, the easier it will be for an advocate of the simulationist view to fit the emotions into their account. At first sight, it seems as though the prospects look good for a simulationist in this area. Many analytic philosophers who have written on the emotions have defended cognitive theories of the emotions (e.g. Solomon 1973, Lyons 1980, de Sousa 1987, Greenspan 1989, Nussbaum 1991). It is characteristic of such theories that they do play up the similarities between emotions and cognitive mental states - in contrast to older accounts which emphasized similarities between emotions and sensations. So, for example, we have treatments of the emotions which focus on the fact that they are intentional states, that they are subject to rational assessment, that they play a role in practical reasoning, and so on.

Of course, there are important differences between the different sorts of views on offer. On some views, emotions are constituted wholly or partly by certain kinds of belief and desire (Nussbaum 1991, 1994, 2002, Lyons 1980), while on others, beliefs and desires are necessary but not sufficient for the occurrence of certain types of emotion; ${ }^{17}$ on some views assessing the rationality of an emotion is just a matter of assessing the rationality of its component beliefs and desires (Solomon 1973) while on others the rationality of emotions is sui generis (de Sousa 1987) and so on. And furthermore, there are important difficulties that any advocate of a cognitivist account of the emotions needs to face up to-most notably problems about the phenomenological side of the emotions, and about whether it is possible to hold that conflicting emotions about a particular situation are irrational in the way in which conflicting beliefs would be (Greenspan 1984, 1989).

Despite these problems, it is worth considering whether we can formulate an account of emotion attribution which is compatible with the simulationist view, and which draws on one or more of the cognitive theories of emotion that are on offer. Two separate questions need to be addressed here. First, which elements of the simulationist picture are going to be incorporated into the account of emotion attribution? Second, which of the many cognitive accounts of emotion is the one to be preferred?

There are at least two ways in which an advocate of simulationism might try to incorporate the emotions into their account of mental state attribution. One way is to focus on the role of emotions in deliberation. This strategy has at least two variants: it might focus on the emotions as being the end products of deliberation, or as inputs into it. The first variant seems implausible. ${ }^{18}$ Emotions do not

(C) Blackwell Publishing Ltd. 2003 
normally strike us as the sort of mental state that is arrived at by deliberation. This prephilosophical intuition can be backed up by reflecting on the facts that in many cases emotions come over us suddenly and that we often find it difficult to give an account of what has led up to them. These are not features that we would expect emotions to have if they were typically reached by means of deliberation, for deliberation is normally a self-conscious process and one which the subject of deliberation is capable of giving some sort of account of. The account may not follow the details of every train of thought that the deliberator engaged in. Nevertheless it will normally help to indicate the reasons which the deliberator takes to support his conclusion.

One objection to this line of thought is that it is not alway implausible to regard emotions as being arrived at by means of deliberation. Consider a situation where I am faced by a moral dilemma. For example, suppose I am wondering how to grade a paper by an able but lazy student. The paper is philosophically excellent, but has been handed in shortly after a deadline which I have announced to my students well in advance and which, I have informed my student, I will apply very strictly. I also know that the student in question is in danger of having to repeat a year, or face some other fairly stringent penalty if they do not receive a good mark for the paper. One question I can ask myself is what I ought to do in such a case. But another question, which I may well ask on the way to answering this question is 'How ought I to feel about this?'. Often, though not invariably, an answer to this question will have an appreciable bearing on how I do feel.

One response to this sort of case would be to say that it is misdescribed as a case of wondering what I should feel: it is instead a case of wondering what I do feel. This seems wrong though. For it may very well be that in such a case I am perfectly clear about what I do feel (annoyed, perhaps, or alternatively sympathetic.) What I am wondering about is whether it is reasonable to feel this way. However it is not clear that even in this sort of a case, we have a case of an emotion being the conclusion of a deliberation. Another possibility is that the conclusion of a deliberation was nothing more than a belief about what I ought to feel, with the appropriate emotion following (if I am lucky) by means of an arational causal mechanism.

At this point we are near to some deep waters in philosophical psychology. There is clearly some relationship between the question of whether deliberations can have emotions as conclusions and the question of whether the conclusion of a piece of practical reasoning is an action. Those who believe that the answer to the second question is 'Yes' may be sympathetic to the idea that deliberations can have emotions as conclusions. They may even feel that similar considerations can be brought to bear in both cases.

Rather than address this issue head on I shall explain why I do not think that any arguments that could be brought forward at this point will help to support the view that when we attribute emotions to another person, what we are doing is simulating a process of deliberation which led up to that emotion. The reason is that although cases like the one described do occur, they are not typical of cases

(C) Blackwell Publishing Ltd. 2003 
where we attribute emotions. Furthermore, although we can attempt to attribute emotions to other people in cases like this, they are not the cases in which we are most likely to make successful emotion attributions. In fact if we do try to work out what someone feels by focussing on the question of what they are likely to think they ought to feel we are likely to go astray. For the sad fact is that much of the time people do not think about what they ought to feel, and what they think they ought to feel is often not the same as what they actually do feel.

This line of thought is not conclusive, but does suggest that it might be worth considering a different account of how a capacity to simulate someone's deliberations might yield a capacity to ascribe mental states to them. This is that we might be able to succeed in attributing emotions by considering their role as inputs into practical reasoning. Robert Gordon (Gordon 1986) has suggested that our capacity for attributing beliefs and desires might be explained on the basis of what he calls 'hypothetico-practical reasoning' ${ }^{19}$ The idea here is that when we try to discover what someone believes and wants, we do so by observing a person's actions, and running through a number of different processes of simulated practical reasoning, involving hypothesized beliefs and desires until we come up with one which yields an action that matches the action we observe. An important feature of this account is that according to it our capacity for attributing beliefs and desires derives from a capacity which it is unproblematic to suppose that we have. This is our capacity for reasoning from hypothetical premises to conclusions about how we would act if the world were a certain way. As Gordon observes, our ability to plan for the future requires us to be able to think in just this way.

There are two ways in which this might yield an account of emotion attribution. One would be if emotions fed directly into practical reasoning. Another would be if emotions fed into practical reasoning only indirectly through beliefs and desires to which they gave rise. However both of these models seem to give rise to problems which do not arise in the more straightforward cases where it is only beliefs and desires that are attributed. One problem with the first model is that it is not so clear that there is anything analogous, in the case of emotions to reasoning from a hypothetically held emotion. A problem with the second model is that although hypothetical reasoning might enable one to reason back from an action to a set of beliefs and desires that motivated it, attributing an emotion would involve a second step to take one from the beliefs and desires to the emotion. This is particularly problematic if one thinks - as one might - that these beliefs and desires might underdetermine the experienced emotion - either because two emotions might give rise to very similar beliefs and desires, or because sufficiently similar beliefs and desires might arise in emotionally charged situations and in affectless ones. ${ }^{20}$

\section{IV}

These difficulties suggest that it might be worthwhile to adopt an approach which does not focus on the role which emotions play in reasoning. An

(C) Blackwell Publishing Ltd. 2003 
alternative possibility is to try to exploit an analogy between perceptual and emotional responses. On one version of the simulation theory - namely, that put forward by Jane Heal (Heal: 1998) - what enables mental simulation to get off the ground in the case of beliefs is our capacity for what she calls 'cocognition'. Her characterization of cocognition is as follows:

Cocognition is ... a fancy name for thinking about the same subject matter. Those who cocognize exercise the same underlying multifaceted ability to deal with the same subject matter. So for example, two persons cocognize when each has the same beliefs and interests and reasons to the same further belief. (Heal 1998: 483)

It seems reasonable to think that one of the many facets of the abilities in question here is the ability to recognize instances of a concept when presented with them in perception. So we could describe two peoples recognition of the fact that an object presented to them in perception falls under a given concept as an instance of cocognition - or perhaps 'coperception'.

It seems clear that coperception will have to be part of any plausible simulationist account of mental state attribution; and it also seems clear that the phenomenon exists. How can it help us to give an account of emotion attribution?

A good way of answering this question is to look at an account of emotions which treats them as being analogous to perceptual responses. One such account has been put forward by Ronald de Sousa (de Sousa 1987). According to de Sousa, emotional responses are analogous to judgments involving secondary quality concepts. Responding emotionally to a situation is analogous to forming a judgment of that situation to the effect that it is similar in relevant ways to what de Sousa calls paradigm scenarios for the particular emotion. Paradigm scenarios are situations which I have been taught to recognize as appropriate for evoking the emotion in question. So for example, paradigm scenarios for anger are those in which one is conspicuously wronged and so on. ${ }^{21}$ This leaves room for the idea that some emotional responses can be rationally criticized - for example, if the situation is not sufficiently similar, or not similar in the right respects to the paradigms - for example, if, in the case of anger, the piece of behaviour that I have taken as a slight did not occur, or if it was unintentional, or there were mitigating circumstances and so on - without requiring that emotions be states that are arrived at by means of full-blooded rational deliberation.

It is worth noticing that on this account the sort of rationality which emotions may have, or alternatively fail to have, is full-blooded cognitive rationality - of the sort that beliefs are typically assessed for in theoretical contexts - and not merely instrumental rationality. That is to say, on this view emotions can be assessed as responses to features of the world - or at least of the world as it affects us - rather than as serving or failing to serve goals which we possess independently.

Such an account of the emotions might provide a basis for a simulationist account of emotion attribution. It has two notable advantages. One is that

(C) Blackwell Publishing Ltd. 2003 
although it is a cognitive account, it does justice to the idea that in many cases we are not in control of the ways in which we are emotionally affected. That is to say, it does justice to the idea that in many cases we are passive in the face of our emotional responses. The analogy with perceptual belief formation seems apt here. Except metaphorically, we do not normally see what we choose to see. In fact the analogy can be pressed further, for there are ways in which we can be in control of our emotional responses which seem to have parallels in the case of visual perception. We can avert our gaze from something that we do not wish to acquire perceptual beliefs about, and up to a point at least we can stifle our emotional responses to situations we do not wish to respond to by refusing to think about them. Equally we can develop our emotional responses, or allow them to atrophy in just the way we can develop or spoil our perceptual responses.

One further way in which the analogy between emotional responses and perceptual ones can be developed, is of particular interest in this context. (This is the second important advantage of de Sousa's account.) One weakness of cognitive accounts of the emotions which I alluded to earlier had to do with what I described as the affective or phenomenological side of the emotions. This is particularly true of accounts of emotions that relate them closely to purely cognitive states. This is because it seems plausible to think of beliefs as being phenomenologically empty. In other words, most beliefs are such that it does not make sense to ask what it is like to have that belief. Emotions are very unlike this. Emotions appear to be very good examples of states where it does make sense to ask what it is like to be in that state. But de Sousa's account of emotions seems to be able to cope with this fact very well. For there are plenty of accounts of perceptual belief formation according to which there is something which it is like to form a perceptual belief. ${ }^{22}$

So one way in which a simulationist account of emotion attribution might be developed would be to build on the idea of emotions as being quasi-perceptual responses to the world which different individuals can share. The central idea here would be that the capacity for attributing emotions to other people depends on a capacity for responding to emotionally charged situations in the same way. The reason why it is worth calling it a simulationist account is that on this view at least in standard cases - the capacity for attributing emotions to other people depends on our capacity for responding to emotionally charged situations in appropriate ways.

A skeptic about the simulationist approach might have an objection at this point. The objection would be that the account put forward was not really a simulationist account at all, but a version of the theory view. ${ }^{23}$ The main ground for this objection would be that in appealing to an individual's capacity to learn appropriate responses to paradigm scenarios, the account proposed equips them with what is, in effect, a theory about the emotions. In learning to respond to a situation which another person faced we would, in effect be using the same theory, but in a slightly different way. The fact that the same capacity was used in both cases would be pale into insignificance compared with the fact that this capacity depends on a theory.

(C) Blackwell Publishing Ltd. 2003 
There are two responses to this objection. The first would be to say in teaching someone how to respond appropriately to certain sorts of situations we are teaching them something, but that there is no reason to think that what we are teaching them is a theory. We are certainly teaching them to discriminate between different sorts of situation, and we may even be regarded as having implicitly taught a system of categorisation, but there is no reason to think - pace Quine and others - that every system of classification needs to be backed up by a theory. Indeed there might be reasons for going further than this. If we are teaching someone how it is appropriate to respond to certain sorts of situation we are teaching them something about the normative structure of the world, rather than its causal structure. So what we have taught them - even if someone insists on calling it a theory - is very different from theories of the sort which believers in the theory view have typically postulated to explain our capacity for mental state attribution.

A second point is this. Compare the proposed account of emotion attribution with accounts of belief attribution which have been offered by simulationists. In particular, consider what a simulationist will say about someone who is trying to attribute to another individual a belief about tables. In order to do this the person doing the attributor will have to have learnt something about tables. Indeed it would be natural to say that what they need to know about is tables rather than beliefs about tables. But in fact, part of the point of the simulationist account is that in knowing about tables, I already know quite a bit about beliefs about tables too. However there is no reason to regard this as supporting the theory view. Instead what it shows is that if we postulate a theory about beliefs about tables in order to explain someone's table belief attributions, what we have done is explanatorily otiose.

We can apply this point to the objection in hand as follows. Suppose that we concede that in learning how to respond appropriately to emotionally charged situations, a person has in effect acquired a theory about the emotions. We can still insist that if we accord this theory an explanatory role in explaining how someone attributes emotions to another person, we have added something which is explanatorily superfluous. It is not in virtue of possessing a theory, but in virtue of knowing how to respond appropriately that an individual acquires the ability to ascribe mental states to other people.

\section{V}

So far I have been arguing at high level of generality. This may be enough to make the account seem suspect to some people. If the suspicion derives from the view that generality is always a source of philosophical error then it is selfrefuting. However there are more specific reasons for being suspicious of any attempt to offer a general account of emotion attribution. There are important differences between one emotion and another, between different episodes involving the same emotion, and between different situations in which we are

(C) Blackwell Publishing Ltd. 2003 
able to attribute an emotion to another person. We need to be sure that we are not distorting the complexities of human emotional and cognitive life by fitting it into a single pattern.

Paul Griffiths (Griffiths 1997: 14-16, 241-2 and passim) has recently argued that the various mental states which we call emotions do not form a 'natural kind'. Some are hard-wired instinctive responses; some involve substantial amounts of learned behaviour; some are social constructs with no underlying referent. If Griffiths is right, then it is hard to see how there could be a unified account of emotion attribution. If emotions are not a natural kind, then emotion attributions are not likely to be.

However, matters are not quite so simple as this. For Griffiths does not want to claim that no two emotions have anything interesting in common. This would be a highly implausible view. His position is that in order to make any progress in understanding emotions we need to make a distinction between what he calls 'Basic Emotions' or affect programs which include states such as fear, anger, joy, surprise, disgust, and grief, and 'Higher Cognitive Emotions' such as jealousy, gratitude and love. Nothing that Griffiths says seems to rule out the possibility that what he calls 'affect programs' are a natural kind. If this is right then there is no reason why an advocate of a simulationist view of the emotions should not hold that the simulationist account applies only to what Griffiths calls 'affect programs' and not to everything that has been classified as an emotion. $^{24}$

It might be objected that this response deprives the simulationist account of a great deal of its interest. For it might be thought that the emotions which are of greatest human interest and into which we might have hoped the simulationist account would provide some insight are not Griffiths' affect programs, but what he calls the higher cognitive emotions. In response to this two points can be made. First, even to have a simulationist account of some forms of emotion attribution would represent an advance for the simulationist position. Second, the response is a conditional one. If Griffiths' account of the emotions is correct then the simulationist may have to retreat to the claim that the account only covers affect programs. But in this case, the objection that it fails to provide a comprehensive account of a group of phenomena of more general interest is misplaced: ex hypothesi there is no comprehensive account to be made.

That said, an advocate of the simulationist position might reject the claim that an account which restricted itself in the first instance to what Griffiths calls affect programs could tell us nothing at all about the higher cognitive emotions. For it might be that at least some cases of these emotions involve episodes or sequences of affect programs. For example, most cases of jealousy involve anger and grief, most instances of gratitude involve pleasure and so on. The suggestion being made here is a fairly weak one: it is not that higher cognitive emotions can be analysed as consisting of nothing but sequences of affect programs, but only that they may be partly constituted by them. If so then it is at least possible that attributions of these emotions may also sometimes involve the attribution of contributing affect programs by simulationist means. ${ }^{25}$

C Blackwell Publishing Ltd. 2003 


\section{VI}

A further objection to the generality of the account that I have been putting forward might be based not on differences between emotions but on differences between the sorts of occasion on which emotions are attributed. For example, there is an important distinction between attributing an emotion to someone when the stimulus which elicited that emotion is present, and attributing it when one's belief about the existence of the stimulus is based on inference or testimony. It is arguable that there will be differences between what happens when I hear that a colleague has been asked to share rooms with someone with whom they do not get on and infer that they will probably be fairly annoyed, and what happens when I see the same colleague responding to some verbal needling on the part of the same individual. An adequate account of emotion attribution has to deal with both sorts of cases.

The account which I have sketched so far can deal more easily with the second sort of case than with the first. It is easy to see how a shared quasi-perceptual response can be involved in my attribution of annoyance in the first case because there is something for me to have a perceptual response to. In the second case there is not. There is a natural response here however. This is to appeal to the role of imagination. My suggestion is in effect that the sorts of emotional response that we need to account for in cases where I attribute an emotion to someone when I am not in the presence of the stimulus which elicits the emotion are related to actual emotions in the same way in which visualisation is related to perception.

For this account to be plausible it needs to be the case that by using my imagination I can become sensitive to features of a situation which are not mentioned explicitly in the description of the situation which prompts my imagination. Something like this can clearly happen in the case of visualising a scene. For example, if I read a description of the appearance of the dome of Hagia Sophia in the sunlight of a March morning in Istanbul and find myself imaging the scene, I shall imagine the sky as having some determinate shade of blue, and different parts of the dome as having different determinate shades of pink; I shall represent to myself spatial relationships between different parts of the dome which are not directly mentioned in the description and so on. These features of the scene may not be explicitly mentioned in the description of the scene. If the analogy between emotional and perceptual responses is plausible, then we ought to expect that if a situation which has some sort of emotional significance to it is described to a person, they may be able to generate the right sort of emotional response to it.

The idea that we are capable of emotional responses to described or imagined situations is not merely ad hoc. ${ }^{26}$ It is a commonplace that we are capable of making emotional responses to works of fiction. It is difficult to see how this could be possible if we did not have a capacity for making emotional responses to described or imagined situations. Nor is there any reason to think that the fact that we are capable of making emotional responses to fiction is incompatible with the view that emotions are quasi-perceptual responses.

One might think that that there is a problem lurking in the vicinity. Proponents of cognitive accounts of emotions often have difficulty making their views

C Blackwell Publishing Ltd. 2003 
consistent with the idea that we have emotional responses to works of fiction. Cognitive accounts of emotions often require that for us to have an emotion we have to have beliefs of a certain sort. For example to grieve for someone we have to believe that something terrible has happened to her; to be afraid of something, we have to believe that we are endangered by it. But since readers of Anna Karenina do not really believe that anything has happened Anna Karenina and viewers of The Creature from the Black Lagoon do not believe they are in danger they cannot have the relevant emotions. One might think that a similar problem arises here: if emotional responses are akin to perceptual responses then responses to imagined situations cannot involve actual emotions since they do not involve actual perceptions.

However, the problem is more apparent than actual. One way of resolving it would to be to accept that when we are responding to imagined situations we have responses which cannot be regarded as full-blown instances of emotion but which are analogous to them in important ways. Rather than grieving for Anna Karenina, I am in a state which bears the same relation to my supposition that something terrible has happened as an actual emotion would bear to the belief that soemthing terrible has happened.

In fact, this view has an important advantage as far as the simulationist account of emotion attribution is concerned. It means for the range of cases which we are considering in this section, I do not need to have the emotion which I am attributing to someone else. I do not need to be angry to attribute anger to you, nor afraid to attribute fear to you. This seems independently plausible: as has been remarked before (Goldie 1999), if I had to become angry in order to attribute anger to you, my anger might end up getting in the way of an accurate appraisal of your emotional state.

\section{VII}

Peter Goldie (Goldie 1999) has recently argued that a simulationist account of emotion attribution is unlikely to be central to a full account of emotion attribution. His suggestion is that in order for someone to make a succesful attribution of an emotion to someone by means of mental simulation I will need to draw on information about a person's character and situation which need to be acquired prior to starting on the simulation. I need background information about a person's situation because people do not react to emotional stimuli in a mechanical way: instead emotions have a narrative structure in which our reaction to one event is likely to be conditioned by our reaction to events which have gone before; and I need information about a persons character because in order to make a succesful attribution of an emotion I need to be able to focus on how they will respond to a situation, which may well be different from how I would respond to the same situation.

What Goldie says about the conditions for succesful attribution of emotions seems undeniable. However, it is not obvious that it presents a serious objection to the simulationist position. Clearly, successful simulations are not likely to take place

(C) Blackwell Publishing Ltd. 2003 
in a vacuum. It is true that an understanding of what someone else believes, desires and has experienced is likely to make us better at attributing emotions to them. But there is no obvious reason why this understanding could not have been obtained by simulationist means. Similar points can be made about the importance of understanding another person's character. It is true that if I try to respond to someone's bereavement by thinking about how I would react if similarly bereaved my response is liable to be flat-footed. As Goldie says, what I need to be able to do is to consider how they might feel. However it does not follow from this that the information that I need in order to help me imagine how they feel cannot also have been acquired by means of simulation. Knowing someone's character is a matter of knowing about their deeply held beliefs, the sorts of things which they are likely to desire under certain circumstances, the things which they value and the degree to which they value them and so on. There seems to be no principled reason why knowledge of this sort should be inaccessible to simulation.

Other objections to the view which I am putting forward derive from the account of the emotions which I have relied upon in my exposition rather than the role which I have given to simulation. One such objection is this. It might be argued that in drawing an analogy between emotional responses and perceptual beliefs, I have run together two distinct phenomena that are involved in perception, and that once these phenomena are distinguished it is impossible to make the analogy work in the way in which I want it to.

The two phenomena which I might be held to have conflated are perceptual experiences to the effect that the world is a certain way, and beliefs formed on the basis of those experiences. Arguably, the features of perception that make emotional responses seem like perceptual ones - namely, the passivity of perception, and the fact that there is something which it is like to perceive the world as being a particular way - are features of perceptual experiences, not of beliefs formed on the basis of those experiences. On the other hand, saying that emotional responses are analogous to perceptual experiences rather than to beliefs formed on the basis of perception does not do anything to explain the fact that presented the initial difficulty for the advocate of simulationism - that is to say, the connection between emotion and rational deliberation. ${ }^{27}$

To this objection there are two possible responses. One is to deny that there really are two sorts of phenomena which need to be kept separate here. It is certainly true that on some accounts of perception there is an important distinction between perceptual experiences and the beliefs which one forms on the basis of those experiences. However these accounts are not the only ones on the market. There are also accounts of perception according to which perception is just a matter of belief acquisition - albeit one in which the beliefs acquired are particularly rich and finegrained (Armstrong 1968). If an account of this sort is correct then the objection fails.

However, one may find this response unsatisfactory. There are, after all, good reasons for insisting on a distinction between perceptual experiences and beliefs properly so-called. One such reason is that beliefs are plastic in a way in which perceptual experience is not. In other words, what one believes depends to a very large extent on the other beliefs which one has, whereas what one perceives does

C Blackwell Publishing Ltd. 2003 
not. This is the lesson which we learn, for example, from the fact understanding the Muller Lyer illusion does not prevent us from seeing the two lines involved in the illusion as having different lengths although it does prevent us from coming to believe that the lines are of different lengths ${ }^{28}$ (Fodor 1983). What this suggests is that beliefs have a different functional role from perceptual experiences and it might be thought that this is a good reason for regarding them as distinct phenomena.

There are difficult points in the philosophy and psychology of perception to be negotiated here. Nevertheless one point which does not seem especially controversial is this: the advocate of the view that I am defending can accept the proposed distinction between perceptual experiences and beliefs, provided that she also insists that perceptual experiences are to be regarded as having propositional content. For it is this feature of beliefs, rather than the exact details of their functional role which is important in explaining the fact that beliefs can function as inputs to reasoning. This is because for something to function as an input to reasoning it must be capable of standing as a reason for other mental states, and the only way that a mental state can do this is by having a propositional structure.

The question of whether perceptual experiences do in fact have a propositional structure is one which is difficult to answer. One reason for thinking that they do is that otherwise, for reasons rehearsed in the last paragraph, it is difficult to see how perceptual experiences can provide us with reasons for beliefs, and that the consequence of denying that perceptual experiences can provide us with reasons for belief seems to be to detach our beliefs from any possibility of being justified by the way that the world is (McDowell 1994: Lecture 3, Brewer 1999). However for my purposes it is not necessary to argue that the view that perceptual experiences have propositional content is inescapable, but only to point out that it is a viable, and an attractive theoretical option. ${ }^{29}$ Furthermore, it is not undermined by considerations about the plasticity of belief and the nonplasticity of perceptual experience.

A second objection has to do with the variability of emotional response. De Sousa raises the possibility that the paradigm scenarios that people are taught to recognize might be so different that our emotional responses might in fact not be universally shared (de Sousa 1987: 181-3). That is to say, it might turn out that there were individuals who responded in a unitary way to situations in which we could see no common thread. Or, alternatively it might be that people responded in a unitary way to situations which we could recognize as having something in common with one another, but which did not arouse any affective response in us.

One response to this worry would be to say that it was the product of a form of skepticism that has no warrant once we take on board the fact that human beings' emotional responses are at least partly based in a shared biological nature. Another would be to say that, to the extent that there are differences between the paradigm scenarios that different individuals have learnt to respond to, this places a limit on how well we can expect mental simulation to work. This might also be an area where we might expect simulation to be helped out by theory from time to time. A third response would be to draw on the apparent fact that just as we can develop our perceptual skills, so we can also develop new patterns of emotional response.

C Blackwell Publishing Ltd. 2003 
One further worry is what might be called the 'direction of gaze' problem. In one of her earlier papers on mental simulation Jane Heal (Heal 1986) has argued that in the case of belief attribution - and in particular in the case of belief attributions which are grounded in shared perceptual experiences the simulationist gets things right by suggesting that we do not start by looking out at the world, and then to its effect on the perceiver to whom we are attributing beliefs, but out from the perceiver to the object of their gaze $\mathrm{e}^{30}$. On the account of emotions on offer, something similar ought to apply in the case of emotion attribution. However, it seems as if in the case of the emotions, this is a misdescription of what occurs. For it seems as though, when we are attributing emotions we look to the subject first and foremost, and only as an afterthought to the world. This is because many emotions, unlike beliefs, have characteristic bodily expressions which vary from emotion type to emotion type, and our capacity to respond to such bodily expressions must play some role in explaining our ability to make successful attributions of emotions. If this were not so, then it would be difficult to account for the importance that recognizing the characteristic bodily expression of emotions has for us.

It is not clear what a simulationist's response to this point ought to be. However, one possible line of response would be to push the analogy with the perceptual case even further here. For it seems plausible to say that although we need to look to the subject in order to tell the modality of the emotional responsewhether it be fear, anger, surprise or whatever this will not be enough to fix the intentional content of the emotion. For this, we do need to turn from the subject of the emotion to the aspect of the world which is eliciting the emotional response. Here, focussing on the behaviour of the subject plays a role which is parallel to that, in the case of belief attribution, to that of following the direction of gaze of a subject of perceptual experiences.

\section{VIII}

The aim of this paper has been to articulate a plausible account of emotion attribution in which mental simulation plays a significant role. I do not claim to have shown that no other account is possible. In particular nothing I have said rules out the possibility that an advocate of the theory view might be able to formulate a view in which simulation plays either no role or at best a very marginal one. However, I do claim by giving a detailed account of the role that simulation could have in emotion attribution, I have increased the overall attractiveness of the simulationist view.

\section{Bill Wringe}

Departments of Philosophy and International Relations

Bilkent University

06800 Ankara

Turkey

wringe@bilkent.edu.tr

C Blackwell Publishing Ltd. 2003 


\section{NOTES}

${ }^{1}$ A good introduction to the debate can be found in Davies and Stone 1995a,b. A more critical recent collection is Kogler and Stueber 2000.

${ }^{2}$ I should emphasise here that I take the debate to be primarily one about what happens when we make mental state attributions, and not, for example, about the nature of mental state concepts (although a simulationist account of mental state attribution may have no implications for our understanding of mental state concepts - I am agnostic about this). See section 2 and footnote 14 below for further discussion.

${ }^{3}$ Epistemology of other minds: Goldman 1989, Sorenson 1998; Metaphysical issues: McDowell 1986; Philosophy of Social Science: Kogler and Stueber 2000; and, for good measure moral philosophy: Goldman 1995.

${ }^{4}$ Since Gordon is a major advocate of the simulationist view who has also written extensively on the emotions, one might expect to find some discussion - either of what a simulationist ought to say about emotion attribution or why a simulationist account is not to be expected in (for example) Gordon 1987. But as far as I can see he has nothing directly relevant to say about the issues being discussed here. (One might think that the view of emotions which Gordon puts forward is incompatible with the simulation view, since he seems to hold that a grasp of some kind of theory is needed for understanding emotion concepts, but I am not sure this correct. See footnote 15 for discussion of a related but more general point. In any case, this is not a line of thought which he makes explicit.)

There is some discussion of issues relevant to the topic of this paper in Goldie 1999, Ravenscroft 1998 and Adams 2001. Goldie, whose views I discuss below, seems mostly concerned to argue that simulationism plays at best a fairly marginal role in mental state attribution. To that extent his views and mine are opposed. Ravenscroft argues that the case of the emotions provides an experimentum crucis between the theory view and simulation view - a claim which is challenged by Adams (see footnote 5 below). However, neither of these papers address the question of what a simulationist acccount of emotion attribution might look like in detail.

${ }^{5}$ I take it as being relatively widely accepted that the theory view can provide some account of emotion attribution. Ian Ravenscroft (Ravenscroft 1998) has argued that such an account cannot explain the fact that when we know what emotion someone is experiencing we often know what it feels like for them to experience that emotion. But see Adams 2001 for a rebuttal of this suggestion.

${ }^{6}$ In particular most serious attempts at giving a philosophical account of emotions take seriously the fact that emotions have intentional objects. This fact, and the related point that full-blown emotion attributions do not just involve recognising what kind of emotion is being experienced but also correctly identifying the intentional content are ones which the simulation view is well-equipped to deal with. (By contrast accounts of emotion which, following Ekman (Ekman 1971: 2) stress the role that recognition of characteristic facial expression in emotion attribution strike me as seriously incomplete. Moreover, it is noticeable that some of those who stress the significance of Ekman's work in arguing that the 'output side' of emotion is largely stereotypical still accept that the 'input side' is plastic (see for example Griffiths 1990). So an account which tacks on to Ekman's view a simple story about our knowledge of a theory about the objects which characteristically evoke certain kinds of emotion does not seem adequate either.)

7 Conceivably, someone might accept the point that emotions do not play the same role in deliberation as beliefs typically do, but maintain that they were beliefs nonetheless.

(C) Blackwell Publishing Ltd. 2003 
There is nothing obviously objectionable about this view. However, it does not help the simulationist with the task of explaining how she could give an account of the attribution of such atypical beliefs.

${ }^{8}$ One might worry that by focussing on similarities between emotion and perception, we weaken the case for a simulationist account of emotion attribution - at least if (as many think) perception is not just a species of belief. But even if this view of perception is correct, I shall argue below (pp. 366-7) that perception shares with belief just those features which make a simulationist account of belief attribution viable. See below for further discussion.

${ }^{9}$ Because this is a schematic overview I shall not discuss every objection which has been made to the simulation view. In particular I shall not attempt a detailed discussion of the issue of whether the simulation view can avoid collapsing into a version of the theory view. This is a question which has been discussed at great length in the literature and which I take to have been resolved in the affirmative. But see footnotes 14, 15 and 16 below for further discussion and for more extended treatments Gordon 1995b, Heal 1998b, Wringe 2000.

10 Since very few defenders of the theory view defend explicit views about the nature of theories in general this fact does not place a very strong constraint on the details of the position they hold. Nevertheless, it is worth making explicit, if only to make clear that advocates of the theory view are generally conscious of the need to avoid using the term theory so loosely as to evacuate it of meaning.

11 Advocates of the simulation strategy sometimes argue that there is in fact an important difference of principle between these different sorts of tasks, as a preliminary to arguing that the theory view of mental state ascription cannot possibly be correct. This is not a view which I am defending here, although I am sympathetic to it. For my purposes it is enough that the simulationist view is an alternative to the theory view.

${ }^{12}$ It is worth noticing the modest modal status of this claim. Simulationists need not hold (although they may) that a tacit theory could not in principle be used to simulate someone else's mental processes.

${ }^{13}$ Ripstein 1987 argues that not all model building requires a theory of the domain being modelled. This may be correct. All I am saying here is that some cases of model building may require the possession of a theory about the domain being modelled.

${ }^{14}$ Of course I may need to believe that the model simulates human blood flow accurately before I am prepared to use it for making predictions. But even if one is extremely generous about what is to count as a theory, it is implausible that a single belief like this could constitute one.

${ }^{15}$ Note that on the simulationist view it is the similarities themselves rather than the fact that any individual believes these similarities obtain which is crucial here.

${ }^{16}$ For a simulationist view of mental state attribution to be coherent it needs to be at least consistent with a plausible account of the nature of mental state concepts. Some people hold that since, on the best accounts of mental state concepts, grasp of such concepts involves the possession of a theory, the simulationist view is unacceptable.

This line of argument dismisses the simulation view too cheaply. There is no obvious reason why a simulationist account of mental state attribution should not be combined with a view according to which the meanings of mental state terms are fixed by one's grasp of certain platitudes about mental states along the lines proposed by Lewis (Lewis 1966, 1972). This does not constitute a complete capitulation to an advocate of the theory view because the simulationist can insist that while a grasp of these platitudes is required for an understanding of mental state concepts it does not go very far towards explaining the vast range of mental state attributions that people are actually capable of making.

(C) Blackwell Publishing Ltd. 2003 
I should add that I am only conceding that an account of this sort is likely to be the best account of mental state concepts for the sake of argument. It's worth noting that people who think that the meaning of mental state terms is fixed in this way typically provide only indirect arguments for thinking that an appropriate set of platitudes can be found, and that at least some of the arguments for thinking that such a set of platitudes must exist is that they must do so if our ability to ascribe mental states to other people is not to be a mystery. (For a particularly blatant example of this, see Jackson and Pettit 1987) This procedure clearly begs the question against the simulationist, who is proposing an alternative account of mental state ascription.

I should also note that there is some disagreement in the literature as to whether a view of the sort suggested here is really open to the simulationist. I follow Jane Heal (Heal 1998) and disagree with Peter Carruthers and George Botterill (Carruthers 1996: 37, Botterill and Carruthers 1999) in thinking that if a mixture of theory and simulation is involved in mental state ascription, this counts as a victory for the simulationist. This is because, as Heal points out, the upshot of a mixed position is that the standard cognitive science strategy for explaining human capacities is not the right way to explain our capacity for mental state ascription; and that this is true for principled reasons to do with the nature of the mental, and which has no parallel in other cognitive domains. But this discussion is tangential to the main concern of this paper, which is not to decide whether a particular view is rightly called simulationist, but to make a claim about what form emotion attribution can take if simulation plays some role in the process.

${ }^{17}$ Nussbaum 1991 discusses but rejects such a view.

18 The view might plausibly if tentatively be attributed to Solomon 1973.

${ }^{19}$ It is perhaps worth making it clear that this account is intended to be a version of the simulationist view, albeit one that turns out to be unsatisfactory in accounting for our ability to ascribe emotions

${ }^{20}$ It is possible that the arguments put forward in this section explain why Gordon seems unwilling to give a simulationist account of emotion attribution. In particular his views about the disanalogies between emotions and action (Gordon 1987: chapter 5) seem relevant here.

${ }^{21}$ de Sousa's views are sometimes criticised for being unduly accommodating to social constructivism. One ground for this charge might be his idea that we have to be taught to recognise that certain situations are relevantly similar to the paradigm cases. But while it is certainly true that de Sousa writes like a social constructivist at times (eg de Sousa 1986: 183-4) it is not clear that the basic view that I am attributing to him needs to be read in a social constructivist way. The fact that we have to learn to see certain things as similar to other things in significant ways need not mean that the similarities themselves are not 'out there' in the world. Furthermore, as Griffiths has pointed out (Griffiths 1990), most theorists of emotion are prepared to conceded that there is room for variability in the objects of emotions on what is often called the 'input side' of emotions: the weak point of social constructivism is the claim that output sides of emotions are socially constructed.

${ }^{22}$ I should emphasise that I am only claiming that this is an advantage of the account of the emotions under discussion, not that it supports the simulationist account of emotion attribution which I am arguing for.

${ }^{23}$ For clarity's sake I should say the point of this paragraph is only to discuss a possible objection to the particular account that I am putting forward, not to discuss the more general charge that simulationism must collapse into a version of the theory view (e.g. because this is the only way to avoid Cartesianism). This issue has been discussed at length in the literature but is not my main concern here. See footnote 16 for further brief

C Blackwell Publishing Ltd. 2003 
discussion and Wringe 2000: chapter 6 for a chapter length discussion of the charge of Cartesianism.

${ }^{24}$ Griffiths is notoriously hostile to what he calls 'propositional attitude' accounts of emotions (see Griffiths 1997: chapter 2). So one might wonder whether one could consistently hold the view that affect programs were a natural kind and (a restricted version of) de Sousa's view that they are analogous to perceptual responses. However, although Griffiths regards de Sousa as holding a version of the propositional attitude view it is notable first that Griffiths does not discuss de Sousa's views directly; secondly that the criticisms that he makes of the specific views which he does discuss do not seem to apply to de Sousa because, unlike most members of the tradition that Griffiths discusses, he holds that emotions are not to be analysed as being constituted even partly by beliefs and desires; thirdly that since de Sousa is not interested in providing analyses of emotion terms in non-emotion terms he does not engage in much of the pumping of linguistic intuitions that Griffiths finds philosophically objectionable; and most significantly that Griffiths concedes (Griffiths 1990: 43, footnote 1) that the general arguments which he takes to dispose of the propositional attitude view do not have as much force against de Sousa as other propositional attitude theorists. (Furthermore Griffiths association of de Sousa with a social constructionist view in this footnote seems wrong-headed for reasons discussed in footnote 21 above.) Finally, one of the most notable claims that Griffiths makes when arguing for a distinction between emotions and higher cognition is that emotions are modular. But that should be no obstacle to seeing emotions as analogous to perception (and hence as propositional attitudes if perceptions are to be counted as propositional attitudes - see pp. 366-7 below for relevant discussion) given the widely held view that perception is modular (Fodor: 1983).

${ }^{25}$ Why not argue for a simulationist account which applied only to higher cognitive emotions and not affect programs? One reason is that one might well think that no unifying account of the higher cognitive emotions can be given. In that case one would have good prima facie grounds for being skeptical about the viability of a general account of the attribution of higher cognitive emotions.

${ }^{26}$ See inter alia Currie 1990 and Walton 1991 for detailed explorations of these issues.

27 I am grateful to Berys Gaut for insisting on this objection.

${ }^{28}$ I am grateful to Daniel Stoljar for drawing my attention to the relevance of this point.

${ }^{29}$ For criticisms of the view see Bermudez 1998: chapter 3, and Peacocke 2001.

\section{REFERENCES}

Adams, F. (2001), 'Empathy, Neural Imaging, and the Theory versus Simulation Debate', Mind and Language, 16: 368-393.

Armstrong, D. (1968), A Materialist Theory of the Mind. London: Routledge and Kegan Paul. Bermudez, J. (1998), The Paradox of Self-Consciousness. Cambridge MA: MIT Press.

Botterill, G. (1996), 'Folk Psychology and Theoretical Status' in Carruthers and Smith (1996).

Botterill, G. and Carruthers, P. (1999), The Philosophy of Psychology. Cambridge: Cambridge University Press.

Brewer, B. (1999), Perception and Reason. New York: Oxford University Press.

Carruthers, P. (1996), 'Simulation and Self-knowledge: A Defense of Theory Theory' in Carruthers and Smith (1996).

(C) Blackwell Publishing Ltd. 2003 
Carruthers, P. and Smith, P. K. (1996), Theories of Theories of Mind. Cambridge: Cambridge University Press.

Currie, G. (1991), The Nature of Fiction. Cambridge: Cambridge University Press.

Davies, M. (1994), 'The Mental Simulation Debate', Proceedings of the British Academy, 83: 99-127.

Davies, M. and Stone, T. (1995a), Folk Psychology. Oxford: Blackwell.

- (1995b), Mental Simulation. Oxford: Blackwell.

de Sousa, R. (1986), The Rationality of Emotion. Cambridge MA: MIT Press.

Ekman, P. (1971), 'Universals and Cultural Differences in the Expression of Emotion', in J. K. Cole (ed.), Nebraska Symposium on Motivation 4. Lincoln, Nebraska: University of Nebraska Press.

Fodor, J. (1983), The Modularity of Mind. Cambridge MA: MIT Press.

Goldie, P. (1999), 'How We Think of Others' Emotions', Mind and Language, 14: 394-423.

Goldman, A. (1989), 'Interpretation Psychologised', Mind and Language, 4: 161-85.

- (1995), 'Empathy, Mind and Morals' in Davies and Stone (1995b).

Gordon, R. (1986), 'Folk Psychology as Simulation', Mind and Language, 1: 158-171.

- (1987), The Structure of Emotion. Cambridge: Cambridge University Press.

- (1995a), 'The Simulation Theory-Objections and Misconceptions' in Davies and Stone (1995a).

— (1995b), 'Simulation without Introspection or Inference from Me to You' in Davies and Stone (1995a).

Greenspan, P. (1980), 'A Case of Mixed Feelings - Ambivalence and the Logic of Emotion', in A. Rorty (ed.), Explaining Emotion. Berkeley: University of California Press.

- (1988), Emotions and Reasons. New York: Routledge.

Griffiths, P. (1990), 'Modularity and the Psychoevolutionary Theory of Emotion', Biology and Philosophy, 5: 175-196.

- (1997), What Emotions Really Are. Chicago: University of Chicago Press.

Heal, J. (1986), 'Replication and Functionalism' in Davies and Stone (1995a).

- (1994), 'Simulation Versus the Theory Theory - What is at Issue?', Proceedings of the British Academy, 83: 129-144.

_ (1996), 'Simulation Theory and Content' in Carruthers and Smith (1996).

- (1998), 'Co-cognition and Off-line Simulation: Two Ways of Understanding the Simulation Approach', Mind and Language, 13: 477-496.

Kogler, H. and Stueber, K. (2000), Empathy and Agency: The Problem of Understanding in the Human Sciences. Boulder CO: Westview Press.

Lewis, D. (1966), 'An Argument for the Identity Theory', Journal of Philosophy, 63: 17-25.

- (1972), 'Psychophysical and Theoretical Identifications', Australian Journal of Philosophy, 50: 249-258.

Lyons, W. (1980), Emotion. Cambridge: Cambridge University Press.

McDowell, J. (1985), 'Functionalism and Anomalous Monism', in E. LePore (ed.), Actions and Events. Oxford: Blackwell.

— (1994), Mind and World. Cambridge MA: Harvard University Press.

Nussbaum, M. (1991), Love's Knowledge. Cambridge: Cambridge University Press.

- (1994), The Therapy of Desire. Princeton: Princeton University Press.

- (2002), Upheavals of Thought. Cambridge: Cambridge University Press.

Peacocke, C. (2001), 'Does Perception Have a Non-Conceptual Content?', Journal of Philosophy, 98: 239-264.

(C) Blackwell Publishing Ltd. 2003 
Ravenscroft, I. (1998), 'What Is It Like To Be Somebody Else? - Simulation and Empathy', Ratio, 11: 170-185.

Ripstein, A. (1987), 'Explanation and Empathy', Review of Metaphysics, 40: 465-82.

Solomon, R. (1973), 'Emotions and Choice', Review of Metaphysics, 17: 20-41.

Sorenson, R. (1998), 'Self-Strengthening Empathy', Philosophy and Phenomenological Research, 58: 75-98.

Stich, S. and Nicholls, S. (1995a), 'Folk Psychology - Simulation or Tacit Theory?' in Davies and Stone (1995a).

Walton, K. (1991), Mimesis as Make-Believe: On the Foundations of the Representational Arts. Cambridge MA: Harvard University Press.

Wringe (2000), 'Theory and Simulation - Two Accounts of Folk Psychology', PhD thesis presented in the School of Philosophy, Leeds University; Leeds University.

(C) Blackwell Publishing Ltd. 2003 